\title{
Constrictor Vulvae
}

National Cancer Institute

\section{Source}

National Cancer Institute. Constrictor Vulvae. NCI Thesaurus. Code C52898.

A striated muscle in the labium, which contracts to constrict the vulva. 